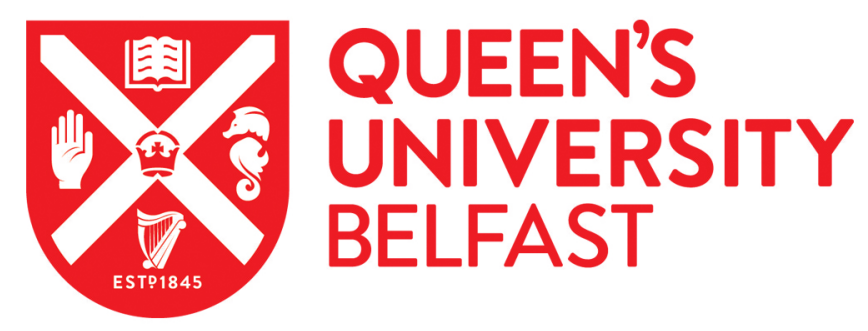

\title{
Supersensitive test of photocatalytic activity based on ISO 22197- $1: 2016$ for the removal of NO
}

Mills, A., Andrews, R., Han, R., O'Rourke, C., \& Hodgen, S. (2020). Supersensitive test of photocatalytic activity based on ISO 22197-1:2016 for the removal of NO. Journal of Photochemistry and Photobiology A: Chemistry, 400, [112734]. https://doi.org/10.1016/j.jphotochem.2020.112734

Published in:

Journal of Photochemistry and Photobiology A: Chemistry

Document Version:

Peer reviewed version

Queen's University Belfast - Research Portal:

Link to publication record in Queen's University Belfast Research Portal

Publisher rights

Copyright 2020 Elsevier.

This manuscript is distributed under a Creative Commons Attribution-NonCommercial-NoDerivs License

(https://creativecommons.org/licenses/by-nc-nd/4.0/), which permits distribution and reproduction for non-commercial purposes, provided the author and source are cited.

\section{General rights}

Copyright for the publications made accessible via the Queen's University Belfast Research Portal is retained by the author(s) and / or other copyright owners and it is a condition of accessing these publications that users recognise and abide by the legal requirements associated with these rights.

Take down policy

The Research Portal is Queen's institutional repository that provides access to Queen's research output. Every effort has been made to ensure that content in the Research Portal does not infringe any person's rights, or applicable UK laws. If you discover content in the Research Portal that you believe breaches copyright or violates any law, please contact openaccess@qub.ac.uk. 
Supersensitive test of photocatalytic activity based on ISO 22197-

\section{1:2016 for the removal of NO}

Andrew Mills*, Rachel Andrews, Ri Han, Christopher O’Rourke and Stephanie Hodgen

School of Chemistry and Chemical Engineering, Queens University Belfast, David Keir Building, Stranmillis Road, Belfast, UK, BT95AG

e-mail: andrew.mills@qub.ac.uk 


\begin{abstract}
A supersensitive test (SST) for photocatalytic activity is described, based on ISO 221971:2016 for the removal of NO, i.e. the standard (NO removal) ISO. The key reaction is the photocatalysed oxidation of nitric oxide (NO) to nitrogen dioxide $\left(\mathrm{NO}_{2}\right)$ by oxygen, which, for most materials, is the dominant reaction at the end of the $5 \mathrm{~h}$ irradiation period employed in the standard ISO. The SST uses the same photoreactor as the standard NO ISO, but with 3 (instead of 1) sample pieces and a flow rate of $0.25 \mathrm{~L} \mathrm{~min}^{-}$ 1 (instead of $3 \mathrm{~L} \mathrm{~min}^{-1}$ ) and, as a consequence, is $36 \mathrm{x}^{\prime}$ s more sensitive than the standard ISO. The SST is used to assess the activities of materials that show little if any activity when tested using the standard ISO, such as commercial self-cleaning samples (such as glass (Activ ${ }^{\mathrm{TM}}$ ), paint and plastic), as well as bank notes. An expression is derived, and verified using films of P25 powder, which relates rate, and so photocatalytic activity, directly to the average \%NO removed, measured under either standard ISO or SST conditions, in the last $15 \mathrm{~min}$ of irradiation, i.e. \% $\mathrm{NO}_{\text {rem, }}$ where the latter value is directly related to the photocatalytic area, $A$, and the reciprocal of the flow rate, $1 / f$. This relationship allows all $\% \mathrm{NO}_{\text {rem }}$ values $<25 \%$, measured using either standard ISO or SST conditions, to be combined to create a universal scale of photocatalytic activity. The universal scale of activity is illustrated using the calculated \% $\mathrm{NO}_{\text {rem }}$ values for high, medium and low activity materials which spans over 3 orders of magnitude of activity. The possible uses of this scale are discussed briefly.
\end{abstract}

Key words: nitric oxide, ISO, photocatalysis, titanium dioxide, low activity 


\section{Introduction}

Semiconductor photocatalysis is an established part of photochemical research, with areas of application as diverse as, the photo-oxidative mineralisation of volatile and non-volatile organics and inorganics (especially $\mathrm{NO}_{\mathrm{x}}$ ), photoinduced superhydrophilicity and photosterilisation [1]. Current commercial photocatalytic products include: (i) self-cleaning glass [2], concrete [3], plastic tent/awning materials [4] and tiles [5], (ii) odour-removing paint for indoor applications [6], (iii) NOx removing paint [7], concrete and tiles for exterior applications, (iv) photo-induced sterile surfaces (ceramics and metals) [8], (v) water and air purification units [1] and (vi) defogging mirrors [1].

The emergence of these photocatalyst-based products has been accompanied by the introduction of a number of international standards to help the photocatalyst industry ensure their products are widely accepted and competitive, and to reassure the customer that the products are of sufficient quality, reproducibility and reliability [9]. Most commercial photocatalytic products developed to date are based on the semiconductor $\mathrm{TiO}_{2}$, because it is: (i) physically, chemically and photochemically stable, (ii) photocatalytically efficient and (iii) inexpensive.

Disappointingly, $\mathrm{TiO}_{2}$ is, however, a large band-gap (i.e. $\mathrm{E}_{\mathrm{bg}}$ is ca. $3.2 \mathrm{eV}$, as anatase $\mathrm{TiO}_{2}$ is usually the preferred crystalline form used in photocatalysis), which means it is only activated by UV light [10]. Fortunately, ca. $5 \%$ of sunlight falls in the UV region and this has allowed the successful commercialisation of a wide number of photocatalytic products for external use $[1,10]$. Not surprisingly, therefore, all the early photocatalyst ISO standards were developed for testing photocatalytic products for outside use and so employed a UV light source to promote the photocatalytic process, such as a black light blue (BLB) fluorescent lamp which, depending on the phosphor employed, emits most strongly at either 365 or $352 \mathrm{~nm}$ [9]. Table 1 lists the current UV-based, ISO photocatalytic standards, which are used to test photocatalytic materials, usually in film form, in terms of their ability to: (i) clean their surface, i.e. 'self-cleaning' materials, (ii) photo-oxidatively mineralise organic or inorganic pollutants in air or water and/or (ii) destroy biological species, such as bacteria, algae, fungi and viruses. Note: a similar set of ISO standards has been developed more 
recently for photocatalytic products which can function under indoor lighting conditions.

Table 1: UV-based published ISO photocatalyst standards

\begin{tabular}{|c|c|c|c|}
\hline Type & Test Method & 1st Published & ISO number \\
\hline \multirow[t]{2}{*}{ Self-cleaning } & $\mathrm{H}_{2} \mathrm{O}$ contact angle & 2009 & ISO 27448-1 \\
\hline & Methylene Blue & 2010 & ISO 10678 \\
\hline \multirow[t]{5}{*}{ Air-purification } & Nitric oxide & 2007 & ISO 22197-1 \\
\hline & Acetaldehyde & 2011 & ISO 22197-2 \\
\hline & Toluene & 2011 & ISO $22197-3$ \\
\hline & Formaldehyde & 2013 & ISO 22197-4 \\
\hline & Methyl mercaptan & 2013 & ISO 22197-5 \\
\hline $\begin{array}{c}\text { Water- } \\
\text { purification }\end{array}$ & Dimethyl sulfoxide & 2010 & ISO 10676 \\
\hline \multirow[t]{4}{*}{ Biological } & Anti-bacterial & 2009 & ISO 27447 \\
\hline & Anti-fungal & 2013 & ISO 13125 \\
\hline & Anti-viral & 2014 & ISO 18061 \\
\hline & Anti-algal & 2016 & ISO 19635 \\
\hline \multirow[t]{4}{*}{ Others } & Light source & 2011 & ISO 10677 \\
\hline & Dissolved oxygen & 2017 & ISO 19722 \\
\hline & Total organic carbon & 2019 & ISO 22601 \\
\hline & Rz ink film reduction & 2018 & ISO 21066 \\
\hline
\end{tabular}

Unfortunately, a number of the most successful of the current photocatalytic commercial products on the market, such as self-cleaning glass, plastics and tiles, are 
poorly served by the current ISO standards. For example, of all the ISO's listed in Table 1, most examples of commercial self-cleaning glass, such as Activ from Pilkington Glass-NSG [2], only work with one ISO test, namely that for methylene blue (MB) degradation, ISO 10678. The situation is even worse for most commercial photocatalytic tiles (such as the Hydrotech technology promoted by Deutsche Steinzeug [11]) and plastics (such as Purify 30 Mesh from Taiyo Kogyio Europe [12]) which exhibit little or no response when tested with any of the current ISOs for photocatalytic materials, including the two developed especially for self-cleaning materials, see Table 1. Unfortunately, the latter two tests appear not to have been developed with the current commercial photocatalytic materials in mind. Indeed, the water contact angle ISO for self-cleaning materials (ISO 27448-1) only works for very active, usually research, photocatalytic films, as it requires the initial destruction of quite a thick layer of oleic acid (ca. $220 \mathrm{~nm}$ ). The latter tests are not really fit for purpose, since most commercial 'self-cleaning' photocatalytic materials are low activity materials. The inherent low activity of many of the current 'self-cleaning' photocatalytic glasses, plastics and tiles, is not too surprising given that they have been developed to maintain a clean surface during the day and so remain cleaner for longer than their 'normal' non-photocatalytic counterparts. As a consequence, in order to function well, such materials need only to remove a surface pollutant faster than its rate of deposition, which is usually very slow, i.e. $\leq 200 \mathrm{~nm}$ per day [13].

It follows from the above that some simple method of measuring the photocatalytic activity of such low activity photocatalytic materials, be they powders or films, needs to be developed. Ideally, such a test should probe the self-cleaning action of the material, but as this is usually a slow process, then it is likely that the test will take quite a time to complete. For example, the self-cleaning glass industries have developed a European standard (BS EN 1096-5: 2016), based on measuring the haze of purposely soiled glass, before and after irradiation, but the irradiation period is long, ca. $16 \mathrm{~h}$ [14]. In addition, this standard can only be used on transparent photocatalytic materials, such as glass, and only allows the material under test to be classed as self-cleaning or not, i.e. it does not provide a reliable measure of self- 
cleaning activity, and so cannot be used to provide a ready comparison in the efficacy of different self-cleaning transparent materials [14].

The above discussion suggests that it would be useful to create a simple measure of the photoactivity of low activity materials, i.e. a super sensitive test, SST, even if it does not provide a direct measure of self-cleaning activity. In this paper we demonstrate that one way to create such a SST, is through a simple modification of the existing photocatalytic ISO for the removal of NO (ISO 22197-1:2016) [15]. The result is a test system that provides a measure of the photocatalytic activity of low activity materials (albeit for NO removal) which allows comparison with other such samples. Interestingly, as we shall see, the combination of the SST with the original (i.e. unmodified) ISO NO removal test, provides what is in effect a universal test of photocatalytic activity, in that it allows a wide range (ca. 3 orders of magnitude) of activities of photocatalyst materials, with very different applications, to be measured and compared. To our knowledge no equivalent SST or universal scale of photocatalytic activity has been reported or proposed before. 


\section{Experimental}

\subsection{Materials}

Unless stated otherwise, all chemicals were purchased from Sigma-Aldrich Chemicals and used as received. The high opacity thin paper (Offenbach bible paper, $50 \mathrm{gsm}$ ) was supplied by Shepherds Bookbinders Ltd., London [16]. The samples of Activ ${ }^{\mathrm{TM}}$ self-cleaning glass [2] and the Purify Mesh 30 [12] were gifts from Pilkington GlassNSG and Taiyo Europe $\mathrm{GmbH}$, respectively. In house, $\mathrm{TiO}_{2}$ films of Evonik P25 [17], StoColor Climasan photocatalytic paint, STO interior and exterior paint, [18]), Greenhouse paint (white Solar Reflective Paint from Fascinating Finishes Ltd.) and solgel $\mathrm{TiO}_{2}$ paste were prepared, as described below, on $50 \mathrm{~mm} \times 100 \mathrm{~mm} \times 4 \mathrm{~mm}$ borosilicate glass plates. Thus, typical thin films of P25 were deposited on the glass substrates by evaporation, at $300{ }^{\circ} \mathrm{C}$ for $2 \mathrm{~h}$, of $10 \mathrm{~mL}$ of a $2.5 \mathrm{~g} \mathrm{~L}^{-1}$ (or $0.02 \mathrm{~g} \mathrm{~L}^{-1}$ ) aqueous suspension of P25 spread over the surface of the substrate $(10 \mathrm{~cm} \times 5 \mathrm{~cm})$ using a plastic syringe [19]. The $\mathrm{TiO}_{2}$ sol-gel nanoparticle film, made using a $\mathrm{TiO}_{2}$ paste and prepared using a previously described sol-gel method [20], was coated onto the glass substrate using a doctor blade technique. Two layers of Sellotape were employed to provide runners on the left and right hands side of the glass samples, with a $120 \mu \mathrm{m}$ gap between the doctor blade (a glass rod) and the underlying glass substrate. $2 \mathrm{~mL}$ of the paste were deposited as a line of material at the top of the plate and drawn down using the glass rod to produce a $120 \mu \mathrm{m}$-thick wet film of the paste over the surface of the glass substrate $(10 \mathrm{~cm} \times 4.7 \mathrm{~cm})$. The $\mathrm{TiO}_{2}$ coating was then annealed at $450{ }^{\circ} \mathrm{C}$ for $60 \mathrm{~min}$, using an initial heating ramp rate of $10{ }^{\circ} \mathrm{C} \mathrm{min}^{-1}$ and then left to cool to room temperature to yield a robust, transparent anatase film approximately $2 \mu \mathrm{m}$ thick, as measured by SEM. The paint coated samples $(10 \mathrm{~cm} \mathrm{x}$ $4.7 \mathrm{~cm}$ ) were prepared using the same doctor-blade technique as that described above for the sol-gel film, but without the final annealing step. All of the above $\mathrm{TiO}_{2}$ coated, substrates were left to dry overnight in the dark before being subjected to pre-conditioning in air by UVA light, $1 \mathrm{~mW} \mathrm{~cm}^{-2}$, provided by two $15 \mathrm{~W}$ blacklight blue light (BLB) fluorescent tubes, which had a peak emission at $352 \mathrm{~nm}$. XRD analysis of all the samples showed that the $\mathrm{TiO}_{2}$ was in its anatase form. 


\subsection{Methods}

Details of the photoreactor used in the standard ISO NO removal test and the protocol therein used to assess the NO removal capacity of different samples have been reported previously $[9,15,19]$.

(1)

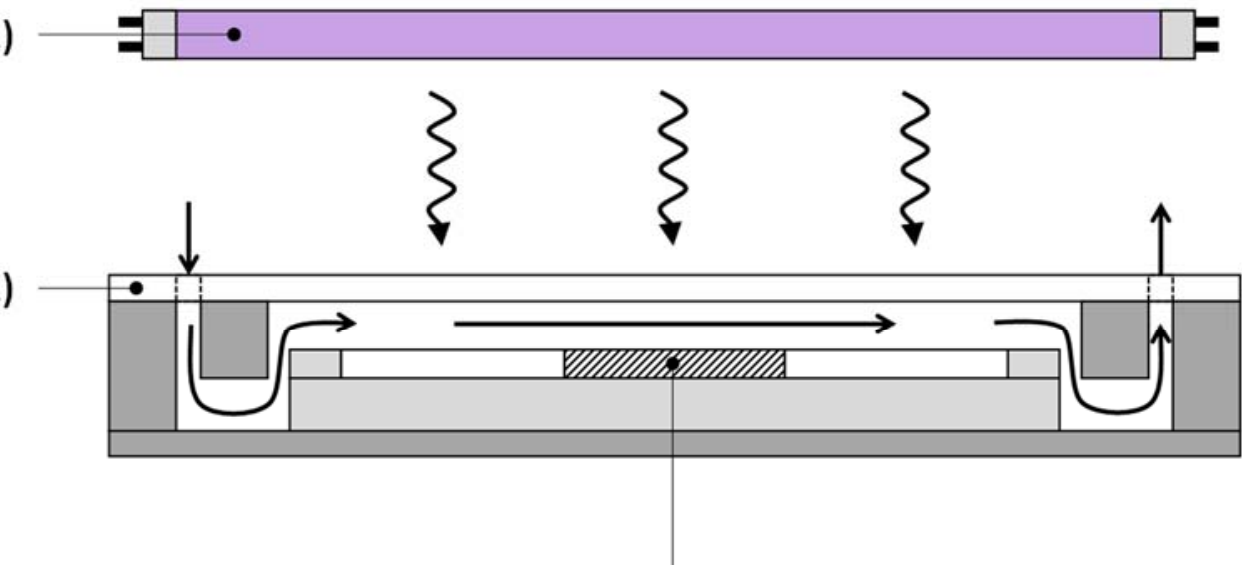

(3)

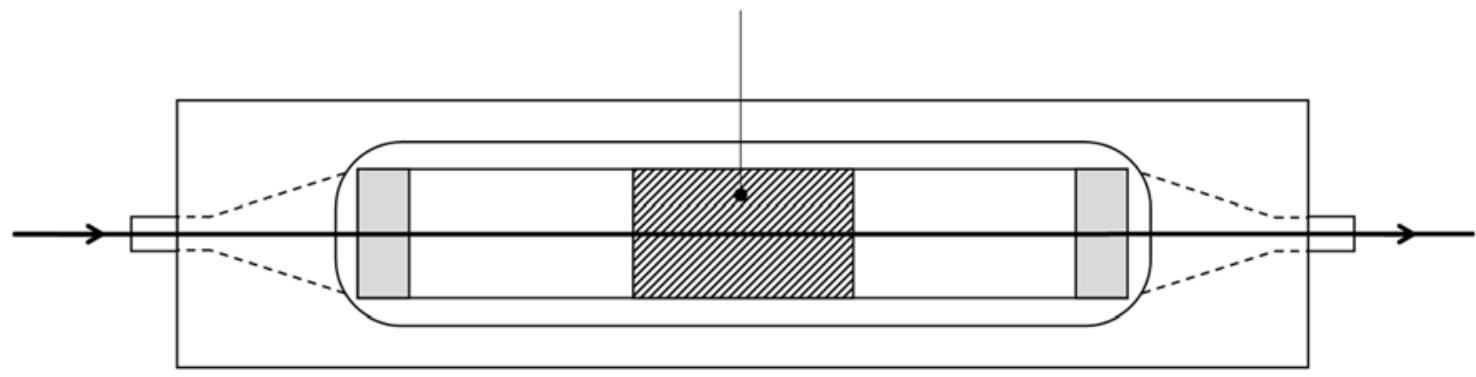

Figure 1: Schematic of the photocatalytic reactor used in the standard ISO NO removal test (ISO 22197-1 [15]). The solid line shows the gas flow, with 1000 ppbv NO (in air with $50 \% \mathrm{RH}$ ) flowing in at $3 \mathrm{~L} \mathrm{~min}^{-1}$. Key features include: (1) $2 \times 8 \mathrm{~W}$ BLB lamps with a $352 \mathrm{~nm}$ emission peak providing an overall UVA irradiance $=1 \mathrm{~mW} \mathrm{~cm}^{-2}$, (2) a borosilicate top-cover window and (3) a $10 \mathrm{~cm} \times 5 \mathrm{~cm}$ plate of the sample under test - set between two other (non-photocatalytic, but removable) plates of identical size.

Briefly, the standard ISO NO removal test, henceforth referred to here as the 'standard ISO test' for brevity, [15] employs an inert flat-bed photoreactor system (Fig. 1) designed to hold three plates, each $5 \mathrm{~cm} \times 10 \mathrm{~cm}$ (i.e. Area, $A_{1}=5 \times 10^{-3} \mathrm{~m}^{2}$ ), of which the test photocatalytic sample is the middle one, and the other two are nonphotocatalytic blank samples, such as plain glass. In any run, all three plates are illuminated with UVA light, delivered by $2 \times 8$ W BLB lamps with a $352 \mathrm{~nm}$ emission peak 
and overall UVA irradiance $=1 \mathrm{~mW} \mathrm{~cm}^{-2}$. Humidified air and dry NO, mixed to give a NO concentration of 1000 ppbv, with a relative humidity of $50 \%$ at $25{ }^{\circ} \mathrm{C}$, are passed into the system at a flow rate, $f, 3.0 \mathrm{~L} \mathrm{~min}^{-1}\left(=50 \mu \mathrm{m}^{3} \mathrm{~s}^{-1}\right)$, via mass flow rate controllers. The gas mixture is made to pass through a narrow gap of $5 \mathrm{~mm}$ between the top borosilicate glass window and the test sample below, and the outlet gas stream from the reactor is sampled through a valve attached to a suitable NOx detection system, based on chemiluminescence [21]. The concentration of NO and $\mathrm{NO}_{2}$ in the outlet stream is monitored for ca. 30 min before the light is switched on, during the $5 \mathrm{~h}$ irradiation period of the test, and for $30 \mathrm{~min}$ after the light has been switched off. The above procedure, used in this work, is slightly different from that detailed in the ISO standard, in which, at the end of the test, it is recommended that the gas stream is switched to the air-only carrier gas at the same time the irradiation is stopped [15]. However, this unnecessary additional gas-switching step is usually ignored by most working on this system [22-26], as it is here, as it has no effect on the key results generated by the reactor. 


\section{Results and Discussion}

\section{$3.1 \% \mathrm{NO}$ removed, $\% \mathrm{NO}_{\text {rem, }}$ and photocatalytic activity}

A typical set of data for a thick (and therefore highly active) P25 film ( $2.5 \mathrm{~g} \mathrm{~L}^{-1}$ coating solution), recorded under standard ISO (for NO removal) test conditions (i.e. one photoactive sample piece, $10 \mathrm{~cm} \times 5 \mathrm{~cm}, 3 \mathrm{~L} \mathrm{~min}^{-1}$ flow rate [15]), is illustrated in Fig. 2.

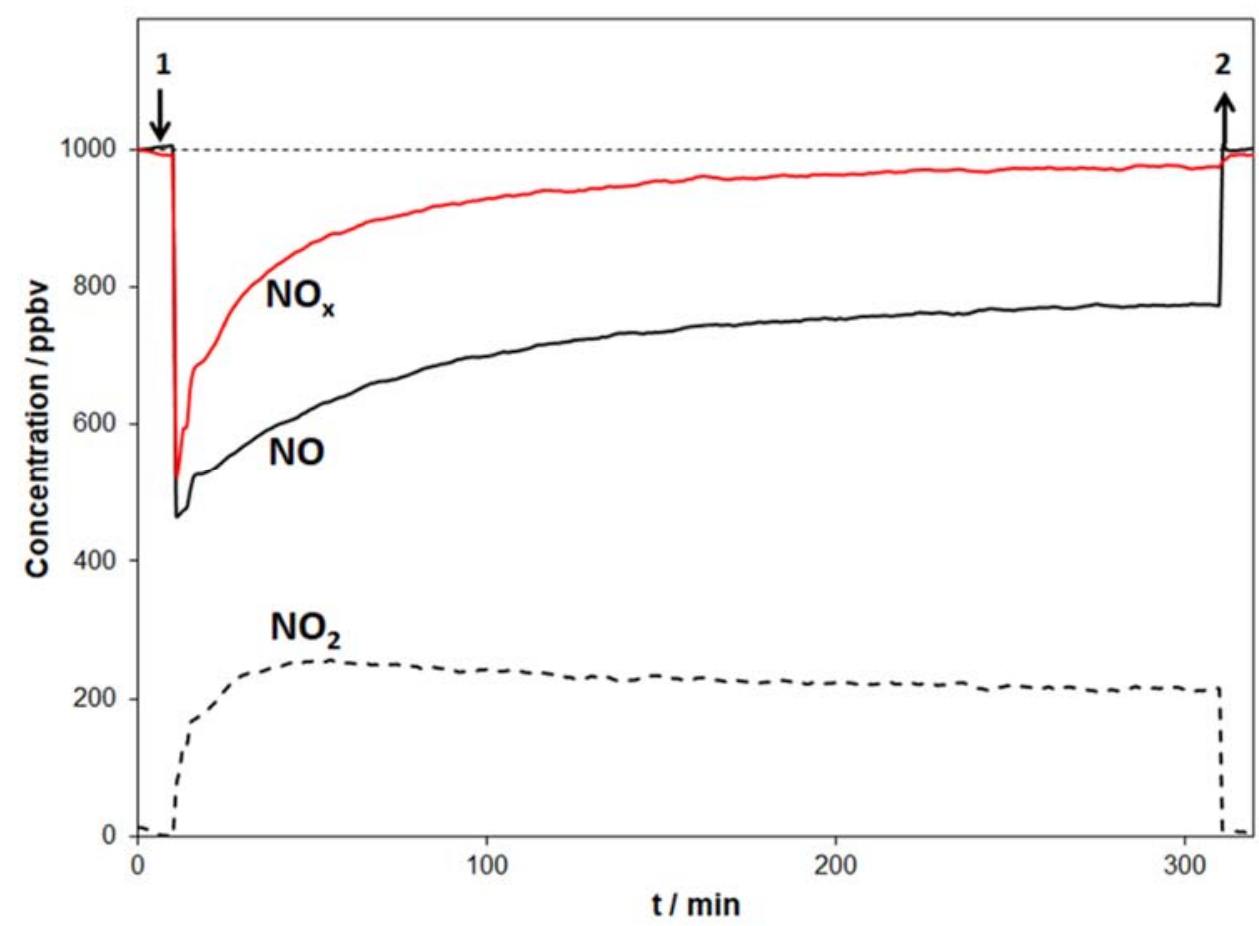

Figure 2: Typical [NO], $\left[\mathrm{NO}_{2}\right]$ and $\left[\mathrm{NO}_{x}\right]$ profiles, recorded for a film sample of $\mathrm{P} 25 \mathrm{TiO}_{2}$ powder (made with a $2.5 \mathrm{~g} \mathrm{~L}^{-1}$ coating solution), as a function of time, with the UV irradiation ( $1 \mathrm{~mW} \mathrm{~cm}{ }^{-2}, 352 \mathrm{~nm}$ ): (1) starting after 15 min and (2) finishing after $5 \mathrm{~h}$ irradiation.

Normally, the test sample's overall ability to remove $\mathrm{NO}_{x}, n\left(\mathrm{NO}_{\mathrm{x}}\right)_{\mathrm{rem}}$ (units: moles) photocatalytically, is taken as the difference between the calculated values of the total $\mathrm{NO}$ removed and $\mathrm{NO}_{2}$ generated during the $5 \mathrm{~h}$ irradiation period [15]. However, for most materials, this average value of $n\left(\mathrm{NO}_{\mathrm{x}}\right)_{\text {rem, }}$ provides a rather distorted picture of the $\mathrm{NO}_{\mathrm{x}}$ removal activity of the material under test in that, during the irradiation, its $\mathrm{NO}_{x}$ removal activity usually decreases significantly with irradiation time and is often zero by the last $15 \mathrm{~min}$ of irradiation, if not well before that time. This common feature of photocatalytic films of decreasing $\mathrm{NO}_{x}$ removal capability, with increasing irradiation time, is well-illustrated in Fig. 2 for the $\mathrm{P} 25 \mathrm{TiO}_{2}$ film, by the plot of the 
overall concentration of $\mathrm{NO}_{\mathrm{x}}$ exiting the reactor at any irradiation time, $t$, versus time (i.e. the red line in Fig. 2), where

$$
\left[\mathrm{NO}_{\mathrm{x}}\right]_{\mathrm{t}}=[\mathrm{NO}]_{\mathrm{t}}+\left[\mathrm{NO}_{2}\right]_{\mathrm{t}}
$$

where $[\mathrm{NO}]_{t}$ and $\left[\mathrm{NO}_{2}\right]_{t}$ (units: ppbv) are the concentrations of $\mathrm{NO}$ and $\mathrm{NO}_{2}$, respectively, exiting the reactor at irradiation time, $t$.

From the plot of $\left[\mathrm{NO}_{\mathrm{x}}\right]_{\mathrm{t}}$ vs $t$ illustrated in Fig. 2 , for a thick P25 film $\left(2.5 \mathrm{~g} \mathrm{~L}^{-1}\right)$, it is clear that although this film of $\mathrm{P} 25 \mathrm{TiO}_{2}$ powder is initially very effective at removing $\mathrm{NO}_{\mathrm{x}}$ by the end of the $5 \mathrm{~h}$ irradiation period it is largely ineffective. All the other photocatalytic samples tested here exhibit the same feature, namely, by the last 15 min of the $5 \mathrm{~h}$ irradiation period in a standard ISO run, the value of $\left[\mathrm{NO}_{\mathrm{x}}\right]_{\mathrm{t}}$ is $c a .1000$ ppbv, i.e. equal to $[\mathrm{NO}]_{\text {in, }}$, the level of $\mathrm{NO}$ before irradiation, and so little or no $\mathrm{NO}_{x}$ is removed in these last 15 min of irradiation.

The cause of the decreasing ability to remove $\mathrm{NO}_{x}$ with increasing irradiation time exhibited by most photocatalytic materials is the accumulation of nitric acid, $\mathrm{HNO}_{3}$, on the surface of the photocatalyst film under test. In the absence of $\mathrm{HNO}_{3}$ the key photocatalytic reactions in a standard ISO reactor for NO removal are as follows:

$$
\begin{aligned}
4 \mathrm{NO}+\mathrm{O}_{2}+2 \mathrm{H}_{2} \mathrm{O} \underset{\mathrm{h} v \geq \mathrm{E}_{\mathrm{bg}}}{\stackrel{\mathrm{TiO}_{2}}{\longrightarrow}} 4 \mathrm{HNO}_{2} \\
4 \mathrm{HNO}_{2}+\mathrm{O}_{2} \underset{\mathrm{hv} \geq \mathrm{E}_{\mathrm{bg}}}{\stackrel{\mathrm{TiO}_{2}}{\longrightarrow}} 4 \mathrm{NO}_{2}+2 \mathrm{H}_{2} \mathrm{O} \\
2 \mathrm{H}_{2} \mathrm{O}+4 \mathrm{NO}_{2}+\mathrm{O}_{2} \underset{\mathrm{hv} \geq \mathrm{E}_{\mathrm{bg}}}{\stackrel{\mathrm{TiO}_{2}}{\longrightarrow}} 4 \mathrm{HNO}_{3}
\end{aligned}
$$

As a consequence, during the initial part of the $5 \mathrm{~h}$ irradiation period, although some of the $\mathrm{NO}_{2}$ and $\mathrm{HNO}_{2}$ escapes the surface, and so cannot be photocatalytically oxidised any further via reaction (3) and (4), there is overall reduction in $\mathrm{NO}_{\mathrm{x}}$, as a significant amount of $\mathrm{NO}$ is converted to $\mathrm{HNO}_{3}$ via the combination of reactions (2)-(4). However, as the irradiation proceeds, the level of $\mathrm{HNO}_{3}$ accumulated on the surface increases, 
which in turn increases the rate of efficiency-lowering, feedback reactions $[19,24]$, such as:

$$
\mathrm{HNO}_{3}+\mathrm{HNO}_{2} \underset{\mathrm{h} v \geq \mathrm{E}_{\mathrm{bg}}}{\stackrel{\mathrm{TiO}_{2}}{\longrightarrow}} 2 \mathrm{NO}_{2}+\mathrm{H}_{2} \mathrm{O}
$$

As a result, with increasing irradiation time, the photocatalytic system tends to one where the overall photocatalysed process is the oxidation of $\mathrm{NO}$ to $\mathrm{NO}_{2}$, i.e.

$$
2 \mathrm{NO}+\mathrm{O}_{2} \underset{\mathrm{h} v \geq \mathrm{E}_{\mathrm{bg}}}{\stackrel{\mathrm{TiO}_{2}}{\longrightarrow}} 2 \mathrm{NO}_{2}
$$

and so $\Delta\left[\mathrm{NO}_{\mathrm{x}}\right]_{\mathrm{t}}=\left([\mathrm{NO}]_{\text {in }}-\left[\mathrm{NO}_{\mathrm{x}}\right]_{\mathrm{t}}\right)$ tends to zero, as is observed in Fig. 2 for the P25 powder film and for all the samples tested here.

It follows from the above that an indirect measure of the photocatalytic activity of any material that can be tested using the standard ISO, or the modified version that is the SST, is the average value of the [NO] measured towards the end of the irradiation, [NO] end; units: ppbv, when sufficient $\mathrm{HNO}_{3}$ has accumulated so that the overall photocatalytic process is the oxidation of $\mathrm{NO}$ by $\mathrm{O}_{2}$ to from $\mathrm{NO}_{2}$, i.e. reaction (6) [19]. In this work, the value of [NO $]_{\text {end }}$ for each sample tested was calculated using the $[\mathrm{NO}]_{\mathrm{t}}$ data measured over the last $15 \mathrm{~min}$ of the irradiation, i.e. from $t=285$ to $300 \mathrm{~min}$. However, a more direct measure of the photocatalytic activity of the material over this period, is the \%NO removed, where the latter is defined as:

$$
\% \mathrm{NO}_{\text {rem }}=100 x\left([\mathrm{NO}]_{\text {in }}-[\mathrm{NO}]_{\mathrm{end}}\right) /[\mathrm{NO}]_{\text {in }}
$$

The value of $\% \mathrm{NO}_{\text {rem, }}$, for any sample, is easy to determine from its recorded [NO] vs $\mathrm{t}$ profile, and, more importantly, is directly related to the average rate of removal of NO (in the last 15 minutes of the irradiation period, $r(\mathrm{NO})$, ), and so its photocatalytic activity with regard to reaction (6), via the following expression [27]:

$$
r(\mathrm{NO})=\% \mathrm{NO}_{\text {rem }} \times[\mathrm{NO}]_{\mathrm{in}} \times 10^{-11} \times f \times \mathrm{P} /(\mathrm{RT} \times A) \mathrm{mol} \mathrm{m}^{-2} \mathrm{~s}^{-1}
$$

For example, in the standard ISO, given: $[\mathrm{NO}]_{\mathrm{in}}=1000 \mathrm{ppbv}, f=50 \mu \mathrm{m}^{3} \mathrm{~s}^{-1}, \mathrm{~T}=298 \mathrm{~K}$ and $A=5 \times 10^{-3} \mathrm{~m}^{2}$, it follows that eqn (8) reduces to:

$$
r(\mathrm{NO})=\% \mathrm{NO}_{\text {rem }} \times 4.09 \times 10^{-9} \mathrm{~mol} \mathrm{~m}^{-2} \mathrm{~s}^{-1}
$$


Since the parameter $\% \mathrm{NO}_{\text {rem, }}$ as defined by eqn (7), is directly related to the rate/activity of the material under test with respect to reaction (6), via eqns (8) and (9), in this work just the variation of [NO] as a function of time profiles are reported here for each sample tested.

\subsection{The super-sensitive NO removal test, SST}

The super-sensitive NO removal test, SST, proposed here is a simple modification of the current standard ISO NO removal test, the modifications being the use of: (i) 3 active sample pieces (each $10 \mathrm{~cm} \times 5 \mathrm{~cm}$ ) in the reactor, instead of just one and (ii) an overall gas flow rate, $f$, of $0.25 \mathrm{~L} \mathrm{~min}^{-1}$, instead of $3.0 \mathrm{~L} \mathrm{~min}^{-1}$. From eqn (8), it follows that for a fixed rate of removal, $r(\mathrm{NO})$, and so activity, the observed $\% \mathrm{NO}_{\text {rem }}$ is proportional to $A / f$, and that the latter parameter is equal to 100 and $3600 \mathrm{~s} \mathrm{~cm}^{-1}$, for the standard ISO and SST, respectively. As a consequence, the SST should be $36 \mathrm{x}$ 's more sensitive than that of the standard ISO NO removal test. Note: this prediction of the degree of increased sensitivity for measuring photocatalytic activity is based on the assumption that the rate of photocatalysis, i.e. $r(\mathrm{NO})$, is independent of the value of $f$ and $A$, and so a (photo)activation, rather than mass transport, controlled process. In order to illustrate the marked sensitivity of the SST, compared with the standard ISO, samples of commercial photocatalytic glass (Activ ${ }^{\mathrm{TM}}$ ) and paint (STO exterior) were tested using both systems and the resulting plots of [NO] vs time are illustrated in Fig. 3. These results show that the photocatalytic activity for NO removal by Activ ${ }^{\mathrm{TM}}$ is almost negligible, when tested using the standard ISO, since $\% \mathrm{NO}_{\text {rem }}<0.5 \%$, but is very marked, and ca. 36 x's bigger, when run under SST conditions $\left(\% \mathrm{NO}_{\text {rem }}=\right.$ ca. $\left.19 \%\right)$. Similarly, whereas STO-exterior paint appears to have a modest, but clearly measurable, activity under standard ISO conditions, $\left(\% \mathrm{NO}_{\mathrm{rem}}=7 \%\right)$, this feature is much more striking, but not 36 x's bigger, when run under SST conditions $\left(\% \mathrm{NO}_{\text {rem }}=\right.$ $84 \%)$.

The latter results highlight a limitation of the SST, which is also a limitation of the standard ISO, namely with increasing measured values of $\% \mathrm{NO}_{\mathrm{rem}}$, the degree of mass transport control in the reactor increases, so that the calculated value of $\% \mathrm{NO}_{\text {rem }}$ becomes less a measure of the fundamental photocatalytic activity of the sample 
under test, which is what is desired, and more a measure of the mass transport conditions in the reactor. In order to limit the degree of mass transport control in the reaction, the measured value for $\% \mathrm{NO}_{\text {rem, }}$ using either the standard ISO or the SST, must be low, typically $\leq 25 \%$. The value of $25 \%$ has been selected here based on the results of this work, vide infra, and other work on samples that exhibit values much above $25 \%$ which do not obey eqn (8) when $f$ is varied. Note, in contrast to eqn (8), where for an activation-controlled reaction $\% \mathrm{NO}_{\text {rem }}$ is proportional to $1 / f$, for a wholly mass transport dependent system, it can be shown that \% $\mathrm{NO}_{\text {rem, }}$ will depend upon $1 / f^{0.5}[28]$. As a consequence, the $S S T$ is only appropriate for measuring the activities of samples that exhibit a $\% \mathrm{NO}_{\text {rem }}$ value $<(25 \% / 36=0.7 \%)$, under standard ISO conditions; so not, for example, suitable for measuring the activity of STO-exterior paint but suitable for measuring the activity of Activ ${ }^{\mathrm{TM}}$. Of course, materials that exhibit a $\% \mathrm{NO}_{\text {rem }}$ value $<0.7 \%$ when tested with the standard ISO would appear largely inactive and it is these, what we shall call here 'low activity materials', that will benefit from being tested using the SST.
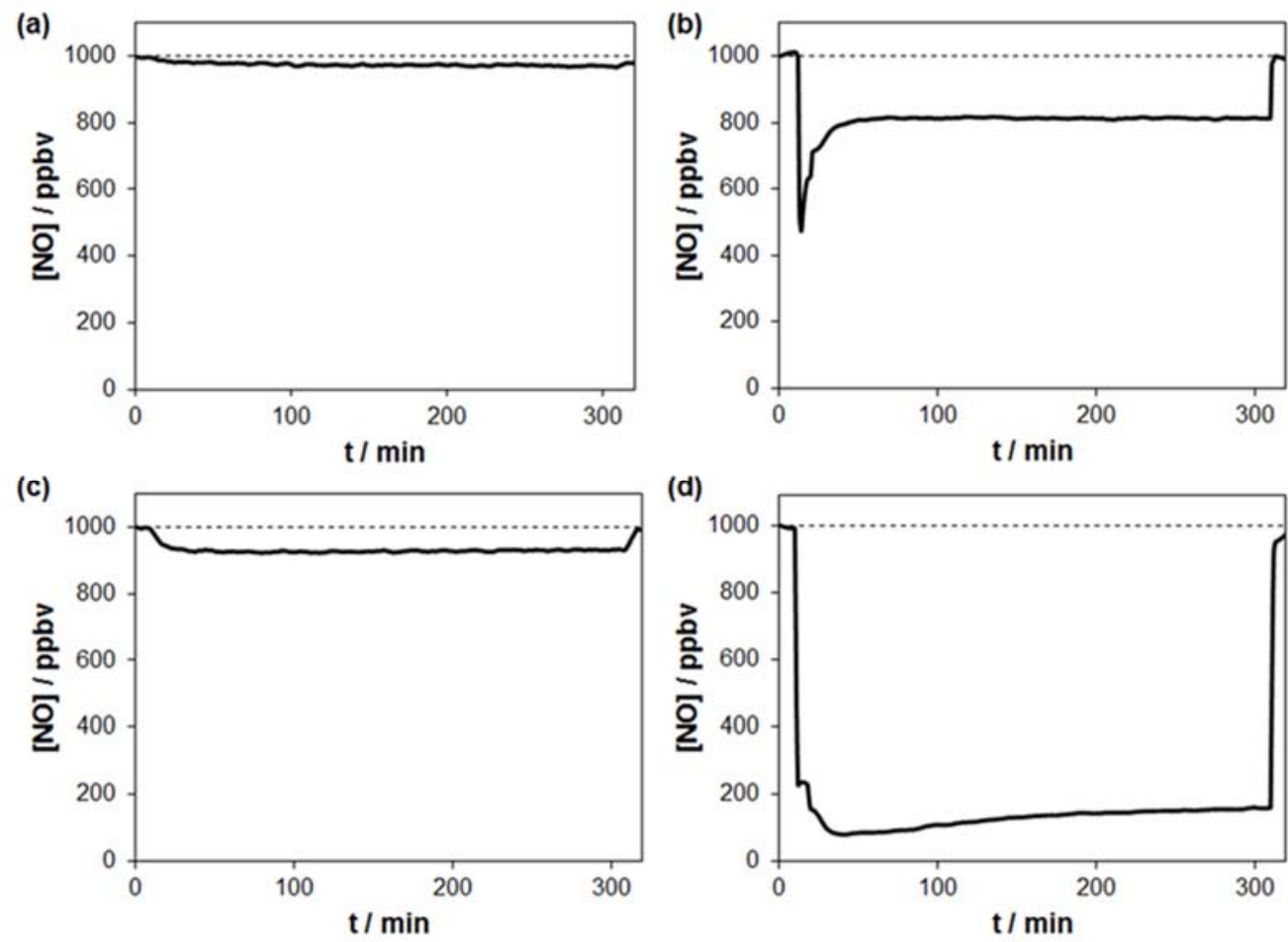

Figure 3: [NO] vs time plots recorded for Activ $^{\mathrm{TM}}$ self-cleaning glass ( $\mathbf{a}$ and $\mathbf{b}$ ) and STOexterior paint (c and $\mathbf{d}$ ), under (from left to right): standard ISO (a and $\mathbf{c}$ ) and SST (b and d) NO removal conditions, respectively. Light on was at $t=15 \mathrm{~min}$ and light off at $\mathrm{t}=315 \mathrm{~min}$. 
As a consequence, the [NO] vs time profiles were recorded using the SST for a number of different samples that showed no activity under standard ISO conditions, i.e. low activity samples. Thus, a very thin coating of $\mathrm{P} 25 \mathrm{TiO}_{2}$, made using a very dilute $(0.02$ $\left.\mathrm{g} \mathrm{L}^{-1}\right)$ coating solution, was tested initially in order to illustrate a film with a reasonable activity $\left(\% \mathrm{NO}_{\text {rem }}=\right.$ ca. $\left.12.1 \%\right)$, as measured using the SST, but less than that of Activ ${ }^{\mathrm{TM}}$. Other samples selected for testing under SST conditions included ones from common items that are not usually recognised as having any photocatalytic activity, and yet use naked (i.e. uncoated) $\mathrm{TiO}_{2}$ as a pigment because of its great ability to scatter light so as to render the product opaque and white. Amongst those selected, obviously no common paint films were tested, since the $\mathrm{TiO}_{2}$ pigment used in these comprise low active or non-active rutile titania particles, surface-treated with alumina or silica, in order to render them passive. However, despite this omission, there remained many other products to choose from, where opacity is also important, but which used less expensive, untreated, and therefore photoactive, $\mathrm{TiO}_{2}$ as the pigment. A notable example of the latter is high-end paper, such as that used in dictionaries, bibles and bank notes [29]. The non-transparency/opacity of such unprotected anatase $\mathrm{TiO}_{2}-$ containing paper is ten times that of talcum powder and calcium carbonate is used and is $15-30 \%$ lighter [29]. Another common commercial product tested, which uses unprotected anatase $\mathrm{TiO}_{2}$, is white, water-based, easily removed (by wiping), paint for the glass in greenhouses, which is used to diffuse the incident sunlight. For the above reasons, samples of bible paper, white greenhouse paint and bank note paper (two 1 US dollar bills, folded to cover the $5 \mathrm{~cm} \times 30 \mathrm{~cm}$ area of the three sample plates) were tested for NO removal photocatalytic activity using the SST and the resulting [NO] vS time profiles are illustrated in Fig. 4. 

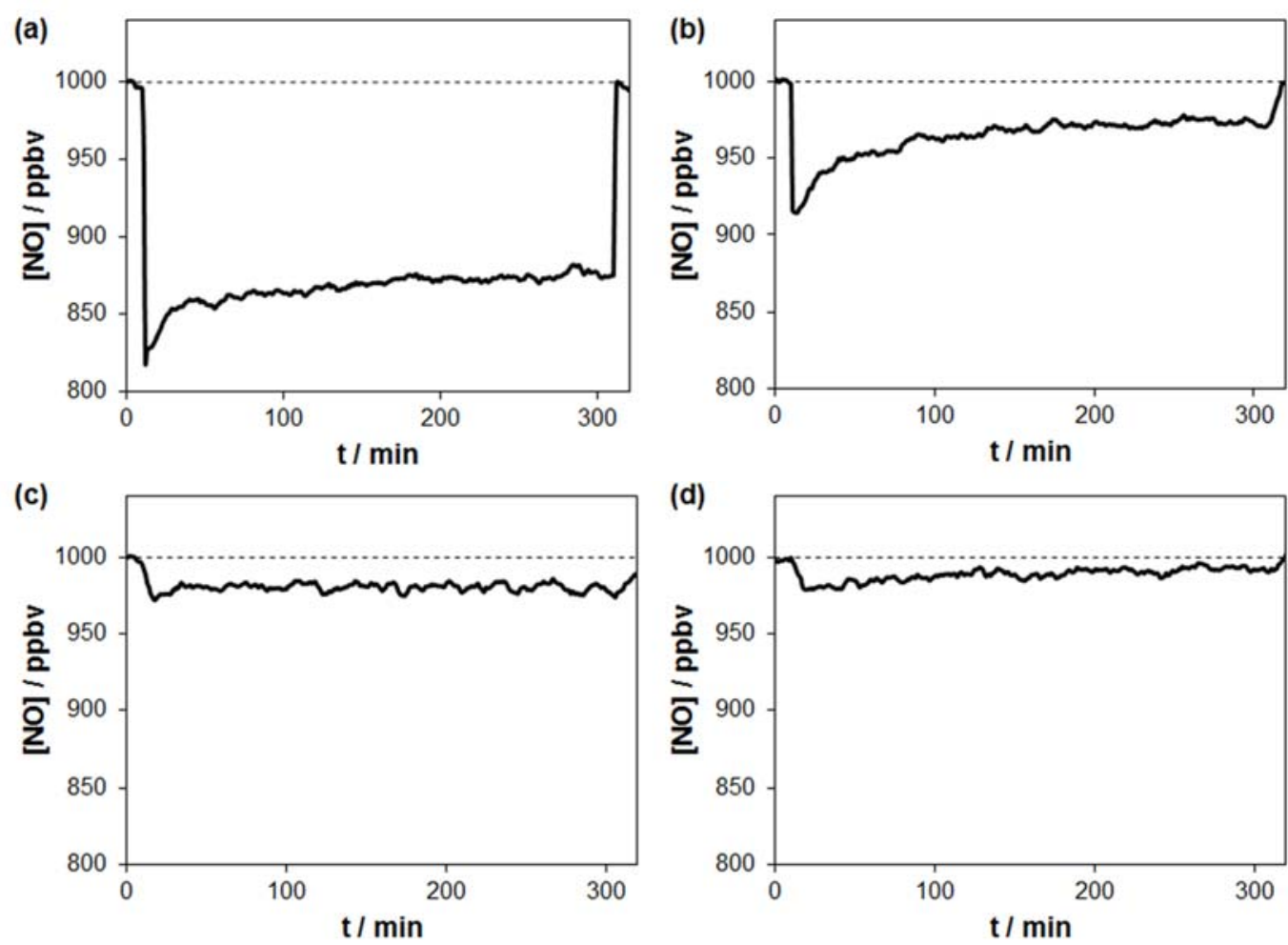

Figure 4: [NO] vs time profiles recorded using the SST for: (a) a P25 thin film (0.02 $\mathrm{g} \mathrm{L}^{-}$ ${ }^{1}$ ), (b) Bible paper, (c) greenhouse paint and (d) bank note paper. Light on was at $t=$ $15 \mathrm{~min}$ and light off at $\mathrm{t}=315 \mathrm{~min}$.

All the samples used to generate the data illustrated in Fig. 4 showed no measurable photocatalytic activity for NO removal when tested under standard ISO conditions, i.e. all were low activity samples, but all were revealed to have some photocatalytic activity under the SST conditions. The bank note paper exhibited the lowest activity of the samples tested and its calculated apparent activity (i.e. $\% \mathrm{NO}_{\text {rem }}=0.4 \%$ ) is near to the limit of detection of the system. The calculated activities of the four different samples were: P25, $0.02 \mathrm{~g} \mathrm{~L}^{-1},(12.1 \%)>>$ Bible paper $(2.6 \%)>$ greenhouse paint $(2.0 \%)>$ bank note paper $(0.4 \%)$, where the figures in parenthesis refer to the associated \% $\mathrm{NO}_{\text {rem }}$ values, calculated using the eqn (7) and the corresponding [NO] data illustrated in Fig. 4, but for the last 15 min of the irradiation.

A plot of the \%NO rem values for all the low activity samples tested using the SST in this work is illustrated in Fig. 5 and shows that Activ ${ }^{\mathrm{TM}}$ self-cleaning glass, is the most active of the ones tested. 


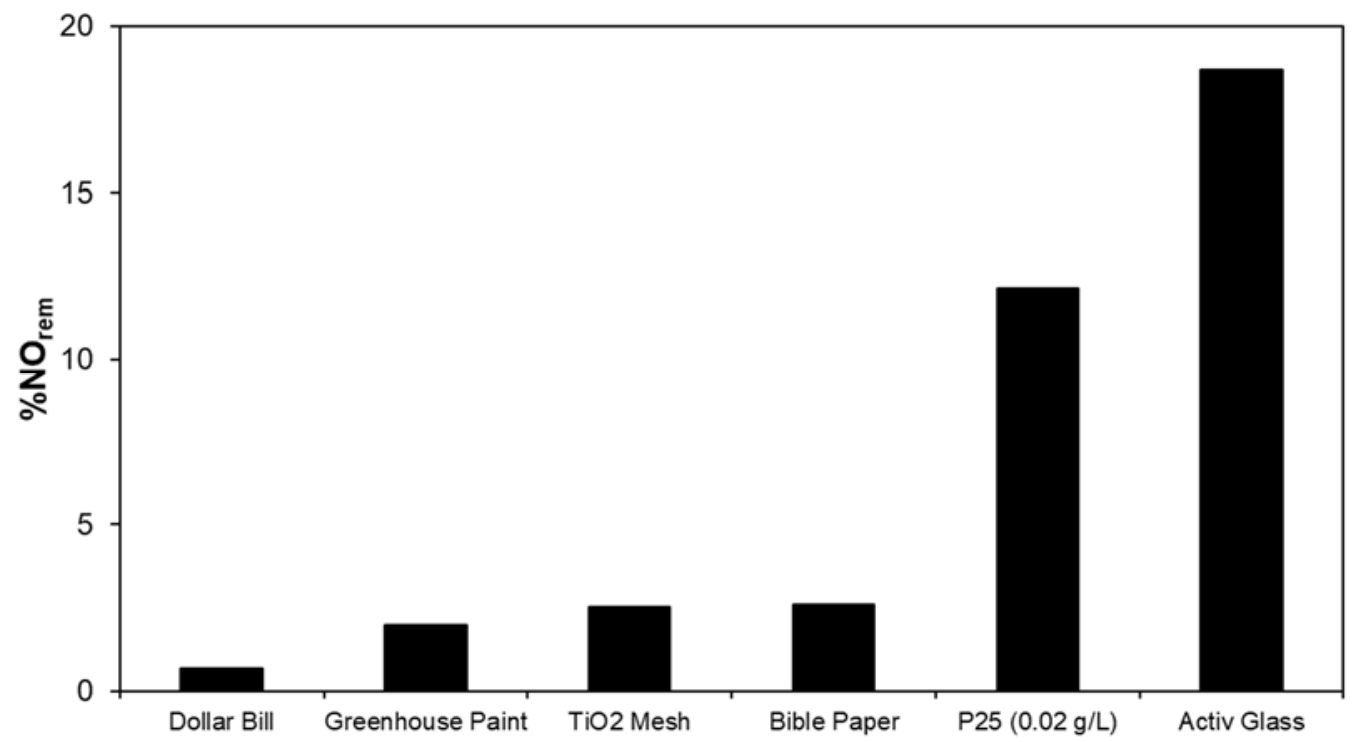

Figure 5: Plot of \% $\mathrm{NO}_{\text {rem }}$ for a series of different low photocatalytic activity samples, where \% $\mathrm{NO}_{\text {rem }}$ was calculate using eqn (7), using the [NO] vs time data (last $15 \mathrm{~min}$ ) recorded for these samples under SST conditions and illustrated in Figs. 2 and 4.

\subsection{Combining standard ISO and SST data}

As noted earlier, if the rate of photocatalysis, i.e. $r(\mathrm{NO})$, of a sample is independent of $f$ and $A$, i.e. dependent on its inherent photocatalytic activity, and not mass transport, in the reactor, then the SST should be $36 \mathrm{x}$ 's more sensitive than that of the standard ISO NO removal test. As noted earlier, whether tested using the standard ISO, or SST, in order for the calculated $\% \mathrm{NO}_{\text {rem }}$ value for a sample to provide a direct measure of its inherent photocatalytic activity, the value of $\% \mathrm{NO}_{\text {rem }}$ should be low, i.e. $<25 \%$. This condition is met for all the samples tested in this report and so it follows from eqn (8) that for all these samples the calculated value of $\% \mathrm{NO}_{\text {rem }}$ should be proportional to the photocatalytic area, $A$ and the reciprocal of the gas flow rate, $f$.

The assumption that $\% \mathrm{NO}_{\text {rem }}$ is proportional to $\mathrm{A} / f$, for moderately low activity samples, as measured using the standard ISO, is implicit in that ISO, which states that if 'the amount of the removal quantity is less than $2.0 \mu \mathrm{mol}$ (about $5 \%$ in removal percentage), the number of test pieces and the flow rate of test gas may be altered'. The standard ISO suggests that for such moderately low activity samples, the sample number should be doubled and the flow rate halved (to $1.5 \mathrm{~L} \mathrm{~min}^{-1}$ ) and the material retested under these new, 'sensitive test', conditions. Interestingly, if such changes 
are made to $A$ and $f$, it follows from eqn (8) that the resulting [NO] vs $t$ data set should yield a calculated value of $\% \mathrm{NO}_{\text {rem }}$ which is $4 \mathrm{x}^{\prime} \mathrm{s}$ bigger than the original value (derived under standard ISO conditions). Thus, a $\% \mathrm{NO}_{\text {rem }}$ value of $5 \%$, determined using the standard ISO, should increase to $20 \%$, if determined under the above 'sensitive test' conditions stipulated by the standard ISO. Curiously, the standard ISO appears to suggest that these changes in $A$ and $f$ would only increase the value of $\% \mathrm{NO}_{\text {rem }}$ by a factor of 2, which is clearly incorrect [15].

The standard ISO for NO removal [15] notes that 'this method can differentiate the samples with different photocatalytic performance' and, from the results illustrated in Fig. 5, it is clear that the SST also has this ability to discriminate between samples of different activity, but for low activity samples. It follows that it should be possible to create a universal scale of photocatalytic activity, based on reaction (6), through the combination of the standard ISO for NO removal and the SST, provided it can be assumed that the data sets generated by the two test protocols are simply related to each other via eqn (8). This simple relationship and underlying assumption can be tested by taking a photocatalytic film, with a maximum $\% \mathrm{NO}_{\text {rem }}$ value $<25 \%$, and: (i) varying the area, $A$, for fixed $f$ and (ii) varying $f$, for fixed $A$, since eqn (8) predicts that the $\% \mathrm{NO}_{\text {rem }}$ is proportional to $\mathrm{A} / f$. The validation of this assumption and simple relationship, as outlined in (i) and (ii), is described below.

\subsection{1\%NO rem vs sample area, $A$}

In order to test, under SST conditions, the above predicted simple relationship between \%NO rem and $A$, for a fixed value of $f$, six $5 \times 5 \mathrm{~cm}$ (i.e. six $25 \mathrm{~cm}^{2}$ ) glass samples were coated with a dilute dispersion of P25 $\left(0.1 \mathrm{~g} \mathrm{~L}^{-1}\right)$. The photo reactor was then loaded with the six, low-activity, P25 coated samples, with a total photocatalytically active area of $150 \mathrm{~cm}^{2}$, and the [NO] vs time profile recorded, with $30 \mathrm{~min}$ no light, followed by $30 \mathrm{~min}$ UV light $\left(1 \mathrm{~mW} \mathrm{~cm}^{-2}\right)$, followed by 30 min no light, under otherwise identical SST experimental conditions, i.e. with $f=0.25 \mathrm{~L} \mathrm{~min}^{-1}$. This process was then repeated with the reactor loaded with five of the P25-coated samples plus 1 blank 5 $\mathrm{cm} \times 5 \mathrm{~cm}$ glass sample to fill the remaining space in the reactor, so that the photocatalytically active area was now $125 \mathrm{~cm}^{2}$. Similarly, four samples plus 2 glass blanks were then tested, and so on, until finally, just one $5 \times 5 \mathrm{~cm}$ low activity P25- 
coated sample, plus 5 glass sample blanks, were tested for NO removal activity. Note: because of the short irradiation period used ( $30 \mathrm{~min}$, instead of $5 \mathrm{~h}$ ), in this part of the work, the value of $[\mathrm{NO}]_{\text {end, }}$ used to calculate $\% \mathrm{NO}_{\text {rem, }}$ via eqn (7), was taken as the average value of $[\mathrm{NO}]_{\mathrm{t}}$ over the last $10 \mathrm{~min}$ (rather than $15 \mathrm{~min}$ ) of the irradiation period. The resulting plot of results in the form of $[\mathrm{NO}]_{\mathrm{t}} \mathrm{vs}$ time profiles for the 6 different photocatalytically active areas, varying from 150 to $25 \mathrm{~cm}^{2}$, is illustrated in Fig. 6 and shows that the value of [NO] end, highlighted by the hatched area, decreases with decreasing P25-coated sample number, i.e. decreasing photocatalyst sample area, $A$. Using this data and eqn (7) to calculate the value for $\% \mathrm{NO}_{\text {rem }}$ at each $A$, a plot of $\% \mathrm{NO}_{\text {rem }}$ vs $A$ was generated which revealed a good straight line with a zero intercept, as expected from eqn. (8), and illustrated by the insert plot in Fig. 6.

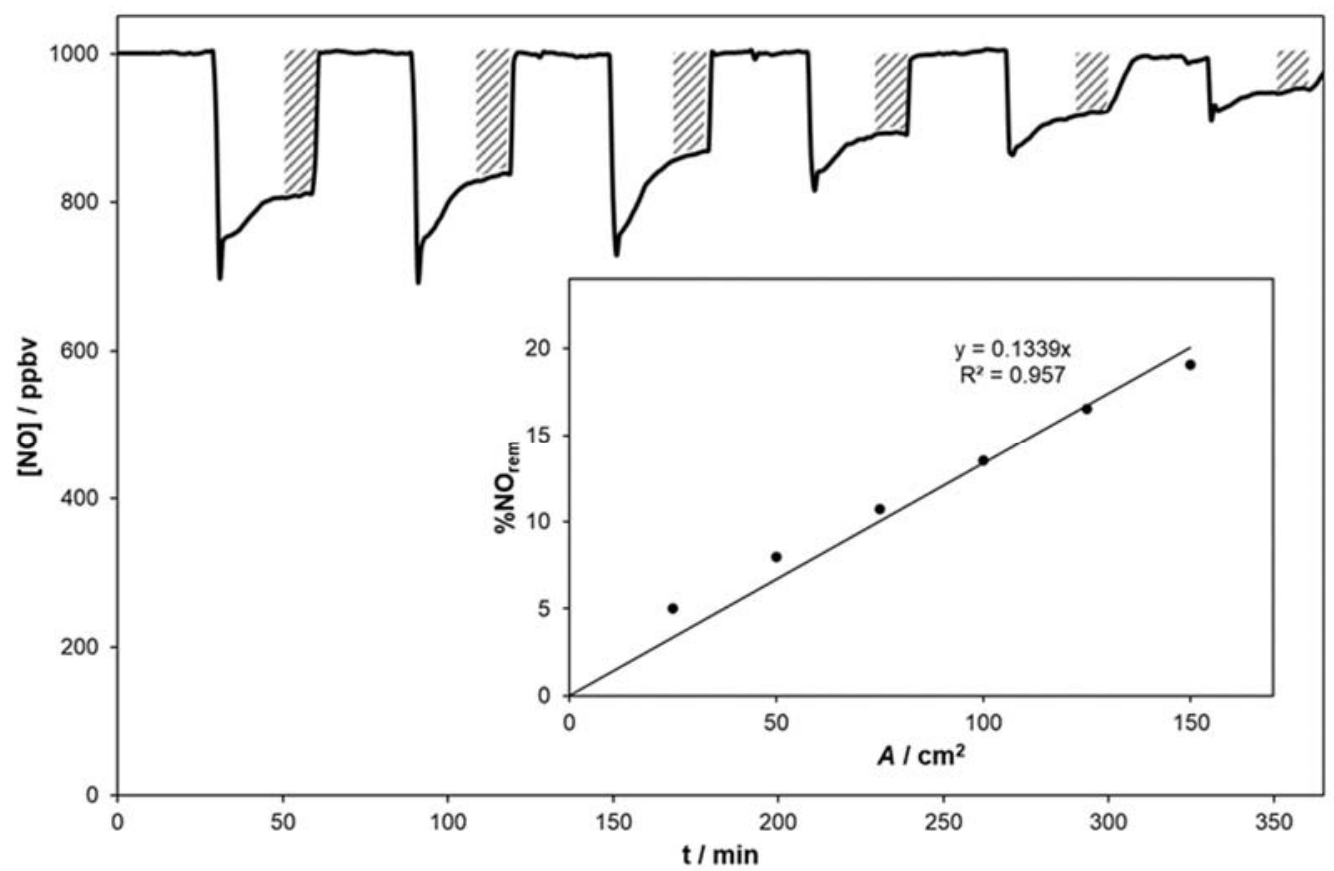

Figure 6: Collected plots of [NO] vs time recorded for different areas of glass coated, but fixed flow rate, $f=0.25 \mathrm{~L} \mathrm{~min}^{-1}$, with a diluted $\mathrm{P} 25$ dispersion $\left(0.1 \mathrm{~g} \mathrm{~L}^{-1}\right)$, tested under otherwise $S S T$ conditions (i.e. $[N O]_{\text {in }}=1000 \mathrm{ppbv}$ and I $=1 \mathrm{~mW} \mathrm{~cm}^{-2}$ ). The photocatalytically active areas used were (from left to right): 150, 125, 100, 75, 50 and $25 \mathrm{~cm}^{2}$, respectively. The insert diagram is a plot of $\% \mathrm{NO}_{\text {rem }} \mathrm{vs} A$, based on the data in the main diagram. 
The same procedure, as outlined above was then repeated, but with $f=3 \mathrm{~L} \mathrm{~min}^{-1}$, and with 6 glass samples coated with a more concentrated, i.e. more active, dispersion of P25 $\left(0.4 \mathrm{~g} \mathrm{~L}^{-1}\right)$. The resulting data set and plot of \% $\mathrm{NO}_{\text {rem }}$ vs $A$ was identical in form to that illustrated in Fig. 6. When taken together the results of this work show that, provided the $\% \mathrm{NO}_{\text {rem }}$ is kept low, i.e. $<25 \%$, then $\% \mathrm{NO}_{\text {rem }}$ is proportional to $A$, for fixed $f$, over the gas flow range 0.25-3.0 $\mathrm{L} \mathrm{min}^{-1}$, in accordance with eqn (8).

\subsection{2 \% NO rem vs gas flow rate, $f$}

As noted above, eqn (8), also predicts that, provided $\% N O_{r e m}$ is always $<25 \%$, then $\% N O_{\text {rem }}$ should be proportional to $1 / f$, if $A$ is fixed. In order to test this, three $10 \times 5 \mathrm{~cm}$ glass plates, coated with a modest amount of P25 $\left(0.15 \mathrm{~g} \mathrm{~L}^{-1}\right)$, were placed in the ISO NO removal reactor and then subjected to a $30 \mathrm{~min}$ period of dark, 30 min irradiation $\left(1 \mathrm{~mW} \mathrm{~cm}^{-2}\right), 30 \mathrm{~min}$ dark, for a series of different gas flow rates, ranging from 3.1 $0.27 \mathrm{~L} \mathrm{~min}^{-1}$. The results of this work are illustrated in Fig. 7 and show that [NO] end decreases with increasing value of $f$. Using this data and eqn (6), a plot of $\% \mathrm{NO}_{\text {rem }}$ vs $1 / f$ was constructed which revealed an excellent straight line with a zero intercept, as expected from eqn. (8) and illustrated by the insert plot in Fig. 7.

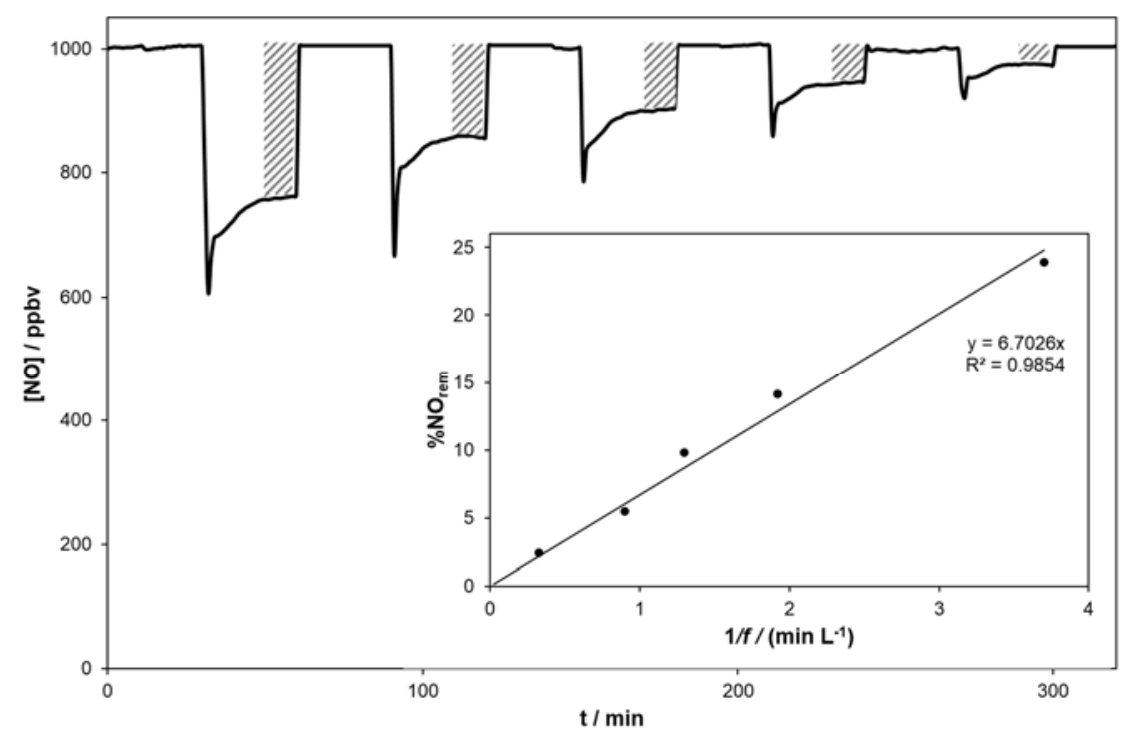

Figure 7: Collected plots of [NO] vs time recorded for different gas flow rates, $f$, but with a fixed photocatalytic area, $A=150 \mathrm{~cm}^{2}$, of glass coated with a diluted P25 dispersion $\left(0.15 \mathrm{~g} \mathrm{~L}^{-1}\right)$, tested under otherwise $S S T$ conditions (i.e. [NO] in $=1000 \mathrm{ppbv}$ and $\mathrm{I}=1 \mathrm{~mW} \mathrm{~cm}^{-2}$ ). The values of $f$ used were (from left to right): $0.27,0.52,0.77$, 1.11 and $3.1 \mathrm{~L} \mathrm{~min}^{-1}$, respectively. The insert diagram is a plot of \%NOrem vs $f$, based on the data in the main diagram. 
These results and those reported in the previous section, suggest that provided of $\% \mathrm{NO}_{\text {rem }}<25 \%$, then eqn (8) holds, and the rate of reaction (6) and, so the calculated value of \% $\mathrm{NO}_{\text {rem, }}$ which is a measure of the rate, see eqn (8), is directly related to the inherent photocatalytic activity of the sample film under test. As a consequence, provided $\% \mathrm{NO}_{\text {rem }}<25 \%$, the $\% \mathrm{NO}_{\text {rem }}$ determined under standard ISO and SST conditions can be combined to create a universal scale of photocatalytic activity for NO removal via reaction (6). Such a scale would allow the ready comparison of high and low activity photocatalytic samples and expand significantly the scope of materials that can be currently tested using existing ISO test systems.

\subsubsection{A universal scale of photocatalytic activity}

For any material tested using either the standard ISO, or SST, the $\% \mathrm{NO}_{\text {rem }}$ value generated can only be reported in terms of the universal scale of photocatalytic activity if the following simple conditions are met:

(1) the $\% \mathrm{NO}_{x}$ removed $\left.\left(=100 x\left\{[\mathrm{NO}]_{\text {in }}-[\mathrm{NO}]_{\text {end }}\right)-\left[\mathrm{NO}_{2}\right]_{\text {end }}\right\} /[\mathrm{NO}]_{\text {in }}\right)$ is very low $(<1-2 \%)$ in the last $15 \mathrm{~min}$ of the illumination period, so that the overall photocatalytic reaction is the oxidation of $\mathrm{NO}$ to $\mathrm{NO}_{2}$, i.e. reaction (6). In our routine testing of many commercial and non-commercial samples, in and outside this work, we have found that this condition is almost always met;

(2) The calculated value for $\% \mathrm{NO}_{\text {rem }}$ is low, i.e. $<25 \%$, so that the photocatalysed reaction is dominated by the inherent photocatalyst activity of the sample with regard to reaction (6), rather than mass transfer. 


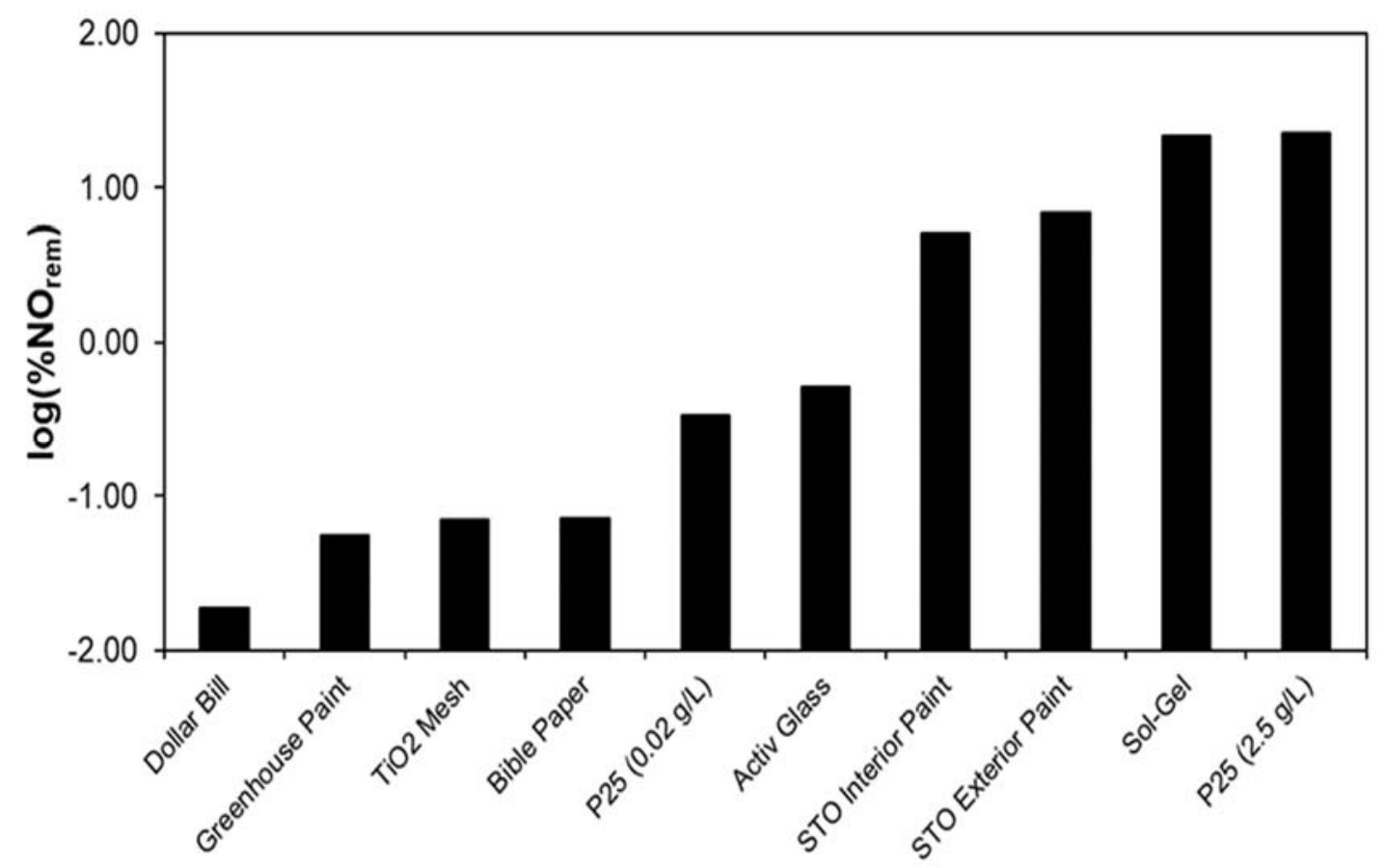

Figure 8: Plot of a universal scale values of $\log \left(\% \mathrm{NO}_{\text {rem }}\right)$ for a series of different, mainly commercial photocatalytic samples, where the values of $\% \mathrm{NO}_{\text {rem }}$ were calculated using eqn (7), using data taken from the appropriate [NO $]_{t}$ vs time profiles, which are mostly illustrated in Figs. 2-4.

Since the above conditions were satisfied by all the samples tested in this work, a plot of the $\log \left(\% \mathrm{NO}_{\text {rem }}\right)$ vs. sample was constructed and is illustrated in Fig. 8; this simple illustration of the universal scale of photocatalytic activity spans over 3 orders of magnitude of activity. This plot shows how a number of different samples, some previously not recognised as having any photocatalytic activity, with very different photocatalytic activities and widely different areas of application, can be readily compared and contrasted on the universal scale created by combining the standard ISO with the SST. This scale allows the comparison between: (i) high activity coatings, such as commercial photocatalytic paint and thick, research-generated P25 and solgel films, which are very effective in purifying water and air, and (ii) low activity samples, such as commercial photocatalytic glass and plastics, which are used as selfcleaning architectural materials. It also helps for the ready identification of previously unidentified photocatalytic materials, such as bible paper, which, given this feature, may lend itself to other applications. 
In this work, the one well-known photocatalytic material that did not show any activity when tested using the SST, was the Hydrotec tile [5]. This material appears to have an exceedingly low activity, which may not be too surprising given the high temperatures used in its production $\left(>1000^{\circ} \mathrm{C}\right.$ ) and, therefore, likely very low particle surface area. Clearly, for such very low activity samples, another type of test is required.

The above universal scale can also be extended to include very high activity samples, i.e. ones which under standard ISO conditions exhibit a $\% \mathrm{NO}_{\text {rem }}$ value $>25 \%$, by simply increasing the flow rate, $f$, (from 3 to $4 \mathrm{~L} \mathrm{~min}^{-1}$, say) or decreasing the area, $A$ (from, $10 \mathrm{~cm} \times 5 \mathrm{~cm}$ to $5 \mathrm{~cm} \times 5 \mathrm{~cm}$, say). Similarly, the SST could be used to assess very low activity materials, like photocatalytic tiles, by decreasing the flow rate, $f$, to values $<$ $0.25 \mathrm{~L} \mathrm{~min}^{-1}$. Thus, through simple changes in $A$ or $f$, the universal scale can be expanded to embrace many more photocatalytic materials, and so span 4 or more orders of activity.

\section{Conclusions}

A supersensitive test, SST, of the photocatalytic activity has been devised based on the photocatalysed oxidation of nitric oxide to nitrogen dioxide, i.e. reaction (6), and utilising the same photoreactor as used in the standard ISO for NO removal (ISO221971:2016 [15], but with 3 (instead of 1) sample pieces and a flow rate of 0.25 (instead of 3) $\mathrm{L} \mathrm{min}^{-1}$. The SST is able to measure the photocatalytic activities of low activity materials, i.e. materials that exhibit very little if any activity when tested using the standard ISO for NO removal or any other photocatalyst ISO. No simple quantitative test of activity for such materials is currently available. The SST allows the ready assessment and comparison of the activities of low activity photocatalytic materials, including commercial products, such as: self-cleaning glass, plastics, paint and paper, some of which are not recognised currently as being photocatalytic.

Provided the calculated $\% \mathrm{NO}_{\text {rem }}$ value, determined for any sample using either the standard ISO or SST, is $<25 \%$, then that value can be taken as a direct measure of the intrinsic photocatalytic rate or activity of the sample for reaction (6). A \% $\mathrm{NO}_{\text {rem }}$ value 
$<25 \%$ for any sample is proportional to $A / f$ and so can be used to create a universal scale of photocatalytic activity for the removal of NO via reaction (6). This universal scale of photocatalytic activity allows comparison in activities not only of like high, medium or low activity samples, but also ones with very different activities, such as photocatalyst air-purifying paints and self-cleaning glass and plastics. No such scale currently exists and so will prove useful to those in research and industry, working on existing and new photocatalytic materials in identifying trends and making meaningful comparisons to other materials which are very different in terms of activity. The proposed SST described above is a simple modification of the current ISO for the removal of NO (ISO 22197-1:2016), which utilises UV light. There is now an ISO for the removal of NO (ISO 17168-1:2018) using indoor (visible only) light, namely a cool white fluorescent light source with UV filter; in all other aspects it is identical to its UV counterpart (ISO 22197-1:2016). It follows that a universal scale of photocatalytic activity for visible light absorbing photocatalysts could be constructed by combining ISO 17168-1:2018, with the SST described above, modified only by the use of a cool white lamp, rather than a UV BLB. This appears particularly relevant as more examples of visible light absorbing photocatalysts for $\mathrm{NO}_{x}$ removal emerge $[30,31]$. 


\section{References}

[1] A. Mills, S. Lee, A web-based overview of semiconductor photochemistrybased current commercial application, J Photochem. Photobiol A: Chem. 152 (2002) 233-247.

[2] Pilkington, https://www.pilkington.com/en-gb/uk/householders/types-ofglass/self-cleaning-glass (Accessed July 2020).

[3] Italcementi, https://www.italcementi.it/it (Accessed July 2020).

[4] TAIYO Europe, https://www.taiyo-europe.com/ (Accessed July 2020).

[5] Hydrotec, https://hytect.com/en (Accessed July 2020).

[6] STO, http: //www.sto.co.uk/en/home/home.html (Accessed July 2020).

[7] Boysen, http://www.knoxoutpaints.com/about.do?id=20800 (Accessed July 2020).

[8] Evonik, https://www.aerosil.com/sites/lists/RE/DocumentsSI/TI-1243-

Titanium-Dioxide-as-Photocatalyst-EN.pdf (Accessed July 2020).

[9] A. Mills, C. Hill, P.K.J. Robertson, Overview of the current ISO tests for photocatalytic materials, J. Photochem. Photobiol. A: Chem. 237 (2012) 7-23.

[10] A. Mills, C. O'Rourke, K. Moore, Powder semiconductor photocatalysis in aqueous solution: an overview of reaction mechanisms, J. Photochem. Photobiol. A: Chem. 310 (2015) 66-105.

[11] Deutsche Steinzeug, https://www.deutschesteinzeug.de/news/presse_und_news_detail.html?nd_ref=2586 (Accessed July 2020).

[12] TAIYO Europe, https://www.taiyo-europe.com/en/materials/pvc (Accessed July 2020)

[13] Y. Paz, Z. Luo, L. Rabenberg, A. Heller, Photooxidative self-cleaning transparent titanium dioxide films on glass, J. Mater. Res. 10 (1995) 2842-2848.

[14] British Standards Institution, (2016), BS EN 1096-5, Glass in building. Coated glass. Test method and classification for the self-cleaning performances of 
coated glass surfaces, Retrieved from

https://shop.bsigroup.com/ProductDetail?pid=000000000030321556.

[15] International Organization for Standardization, (2018), ISO 22197-1, Fine ceramics (advanced ceramics, advanced technical ceramics) - Test method for air-purification performance of semiconducting photocatalytic materials - Part 1: Removal of nitric oxide, Retrieved from https://www.iso.org/obp/ui/\#iso:std:iso:22197:-1:ed-2:v1:en.

[16] Shepherds Bookbinders Ltd, https://store.bookbinding.co.uk/store/ (Accessed July 2020).

[17] Evonik, https://corporate.evonik.com/en/products/searchproducts/pages/product-details. aspx?productld=43469 (Accessed July 2020).

[18] STO, https://www.sto-sea.com/en/about-sto/sto-innovations/stocolorclimasan-/sto-climasan-color-.html (Accessed April 2020).

[19] A. Mills, S. Elouali, The nitric oxide ISO photocatalytic reactor system: Measurement of NOx removal activity and capacity, J. Photochem. Photobiol. A: Chem. 305 (2015) 29-36.

[20] A. Mills, N. Elliott, G. Hill, D. Fallis, J. R. Durrant, R. L. Willis, Preparation and characterisation of novel thick sol-gel titania film photocatalysts, Photochem. Photobiol. Sci. 2 (2003) 591-596.

[21] E.J. Dunlea, S. C. Herndon, D.D. Nelson, R.M. Volkamer, F. San Martini, P.M. Sheehy, M.S. Zahniser, J.H. Shorter, J.C. Wormhoudt, B.K. Lamb, E.J. Allwine, J.S. Gaffney, N.A. Marley, M. Grutter, C. Marquez, S. Blanco, B. Cardenas, A. Retama, C.R. Ramos Villegas, C.E. Kolb, L.T. Molina, M. J. Molina, Evaluation of nitrogen dioxide chemiluminescence monitors in a polluted urban environment, Atmos. Chem. Phys. 7 (2007) 2691-2704.

[22] T. Giannakopoulou, N. Todorova, G. Romanos, T. Vaimakis, R. Dillert, D. Bahnemann, C. Trapalis, Composite hydroxyapatite/ $\mathrm{TiO}_{2}$ materials for photocatalytic oxidation of NOx, Mat. Sci. Eng. B 177 (2012) 1046-1052. 
[23] H. Ichiura, T. Kitaoka, H. Tanaka, Photocatalytic oxidation of NOx using composite sheets containing $\mathrm{TiO}_{2}$ and a metal compound, Chemosphere 51 (2003) 855-860.

[24] T. Sano, N. Negishi, K. Koike, K. Takeuchi, S. Matsuzawa, Preparation of a visible light-responsive photocatalyst from a complex of $\mathrm{Ti}^{4+}$ with a nitrogencontaining ligand, J. Mater. Chem. 14 (2004) 380-384.

[25] T. Sano, N. Mera, Y. Kanai, C. Nishimoto, S. Tsutsui, T. Hirakawa, N. Negishi, Origin of visible-light activity of $\mathrm{N}$-doped $\mathrm{TiO}_{2}$ photocatalyst: behaviors of $\mathrm{N}$ and $\mathrm{S}$ atoms in a wet N-doping process, App. Catal. B: Environ. 128 (2012) 7783.

[26] A. Mitsionis, T. Vaimakis, C. Trapalis, N. Todorova, D. Bahnemann, R. Dillert, Hydroxyapatite/titanium dioxide nanocomposites for controlled photocatalytic NO oxidation, App. Catal. B: Environ. 106 (2011) 398-404.

[27] R. Dillert, J. Stötzner, A. Engel, D.W. Bahnemann, Influence of inlet concentration and light intensity on the photocatalytic oxidation of nitrogen(II) oxide at the surface of Aeroxide $\mathrm{TiO}_{2}$ P25, J. Hazard. Mater. 211-212 (2012) 240-246.

[28] A. Mills, L. Burns, C. O'Rourke and S.Elouali, Kinetics of the photocatalysed oxidation of NO in the ISO 22197 reactor, J. Photochem. Photobiol. A: Chem. 321 (2016) 137-142.

[29] SlideShare, https://www.slideshare.net/fire7teeth/the-applications-oftitanium-dioxide-in-paper-industry (Accessed July 2020).

[30] P. Cheng, H. Liu, Y. Sun, J. Li, W. Cui, L. Wang, W. Zhang, X. Yuan, Z. Wang, Y. Zhang, F. Dong, Bi metal prevents the deactivation of oxygen vacancies in $\mathrm{Bi}_{2} \mathrm{O}_{2} \mathrm{CO}_{3}$ for stable and efficient photocatalytic NO abatement, Appl. Catal. B 264 (2020). DOI: 10.1016/j.apcatb.2019.118545.

[31] B. Lei, W. Cui, J. Sheng, H. Wang, P. Chen, J. Li, Y. Sun and F. Dong, Synergistic effects of crystal structure and oxygen vacancy on $\mathrm{Bi}_{2} \mathrm{O}_{3}$ polymorphs: 
intermediates activation, photocatalytic reaction efficiency, and conversion pathway, Sci. Bulletin 65 (2020) 467-476. 